\title{
Identification of Resistance to Citrus Black Spot Using a Novel In-field Inoculation Assay
}

\author{
Andrew K. Miles
}

Centre for Horticultural Science, Queensland Alliance for Agriculture and Food Innovation, The University of Queensland, Ecosciences Precinct, 41 Boggo Road, Dutton Park, Brisbane, Queensland 4102, Australia

\author{
Malcolm W. Smith \\ Department of Agriculture \& Fisheries, Bundaberg Research Station, 49 \\ Ashfield Road, Bundaberg, Queensland 4670, Australia
}

Nga T. Tran and Timothy A. Shuey

Centre for Horticultural Science, Queensland Alliance for Agriculture and Food Innovation, The University of Queensland, Ecosciences Precinct, 41 Boggo Road, Dutton Park, Brisbane, Queensland 4102, Australia

\section{Megan M. Dewdney}

Citrus Research and Education Centre, University of Florida, 700 Experiment Station Road, Lake Alfred, FL 33850-2243

\section{André Drenth}

Centre for Horticultural Science, Queensland Alliance for Agriculture and Food Innovation, The University of Queensland, Ecosciences Precinct, 41 Boggo Road, Dutton Park, Brisbane, Queensland 4102, Australia

Additional index words. breeding, fruit, infection, Guignardia, pathology, Phyllosticta citricarpa

\begin{abstract}
Citrus black spot is an important fungal disease of citrus resulting in fruit drop and rind blemish in tropical and subtropical production areas. The disease is incited by the fungus Phyllosticta citricarpa (McAlpine) van der Aa (synonym: Guignardia citricarpa Kiely), with control currently relying on the application of fungicides. Because the presence and expression of resistance is poorly understood, we sought to develop a method for inoculating fruit in the field that gives reproducible symptoms of citrus black spot consistent with natural field infection. We subsequently validated this method by screening 49 citrus accessions and characterized their qualitative expression of citrus black spot symptoms. Challenge inoculations were undertaken with a known isolate of $P$. citricarpa, and control fruit were inoculated with water or the endophyte $P$. paracapitalensis Guarnaccia \& Crous. Our results showed that all mandarin, sweet orange, lemon and papeda types were susceptible; pummelo, lime, and sour orange types expressed immunity; while various hybrids were susceptible, resistant and immune. Hybrid progeny from crosses using pummelo [Citrus maxima (Burm.) Merr.] as a parent showed preliminary evidence of segregation for citrus black spot immunity. The implications of these results to achieve genetic improvement for citrus black spot resistance in citrus breeding programs are discussed.
\end{abstract}

Citrus black spot (CBS), incited by the fungus Phyllosticta citricarpa (Kiely, 1948; McAlpine, 1899), is an important disease of citrus in most humid tropical and subtropical growing areas worldwide, including parts of continental Australia, Asia, South America, Africa, and North America (Kiely, 1948; Korf et al., 2001; Kotzé, 1981; McOnie, 1964a; Schubert et al., 2012; Wager, 1952). CBS is characterized by expression of different symptoms on fruit, including hard spot (Fig. 1A), freckle spot (Fig. 1B), virulent spot (Fig. 1C), speckled blotch (Fig. 1D), false melanose (Fig. 1E), and cracked spot (de Goes et al., 2000; Kiely, 1948; Kotzé, 2000).
Severe symptoms on fruit can result in premature fruit abscission, and symptoms similar to hard spot can occasionally be observed on leaves and twigs (Kiely, 1948; Truter, 2010). Pycnidia of $P$. citricarpa often develop within lesions, for example within the hard spot lesions (Fig. 1F). The pycnidia form conidia, which are water dispersed and abundantly produced in vitro (Kiely, 1948; Spósito et al., 2008). Aerial dispersal occurs via sexually derived ascospores released from pseudothecia formed in leaf litter but are more challenging to produce in vitro in large quantities (Kiely, 1948; Tran et al., 2017, 2018; Wang et al., 2016). Fruit are most susceptible to infection up to 16 to 28 weeks after flowering, when the fungus colonizes the rind and remains latent as a knot of mycelium beneath the cuticle (Baldassari et al., 2006; Brentu et al., 2012; Kotzé, 1981; Lanza et al., 2018; McOnie, 1967).

Expression of symptoms typically occurs after the latent mycelium breaks dormancy as fruit reach maturity (Kiely, 1948; Wager, 1952). Control of CBS relies almost entirely on protectant fungicide applications during the susceptible period (Kotzé, 1981; Lanza et al., 2018; Miles et al., 2004; Schutte et al., 2003; Silva et al., 2016), with lesser implementation of cultural practices such as mulching and pruning to reduce the inoculum load and increase tree vigor (Loest, 1968; Miles et al., 2008; Schutte and Kotzé, 1997). Conventional genetic solutions via scion resistance have been largely ignored, with only one preliminary and short-lived attempt to breed for resistance to this disease (Rhodesia Agr. J., 1974).

Defining different levels of resistance to $P$. citricarpa is challenging due to the range of symptoms expressed in the host plant, the long period between infection and symptoms expression, assessment of the different levels of expression, and the varied priorities when assessing fruit. In this study, we used the definitions of D'Arcy et al. (2001) for the terms "immune," "resistant," "susceptible," and "tolerant" with some minor modifications specific to CBS. Thus, "immune" denotes that the host cannot be infected by the pathogen ( $P$. citricarpa cannot be recovered from the point of inoculation); "resistant" denotes that the host possesses properties that allow infection but prevents or impedes symptom development ( $P$. citricarpa can be recovered from the point of inoculation but there are no disease symptoms); and "susceptible" denotes that the host is prone to express disease symptoms when infected by a particular pathogen (typical symptoms of CBS develop at the point of inoculation). "Tolerant" is defined as the ability of the host to endure infection and disease, but in the case of CBS, this depends on the end use of the fruit. For example, studies relating to a juice processing citrus industry may define tolerance on the basis of fruit abscission because this will directly affect economic yield, whereas expression of symptoms on the mature fruit has limited commercial relevance. By contrast, in the case of fresh fruit production, tolerance may be defined in respect to quantitative expression of symptoms as cosmetic blemishes have a major effect on commercial value. Furthermore, if fresh fruit is destined for export to regions for which CBS is a phytosanitary concern, tolerance may not even be considered because these markets insist on the complete absence of symptoms on the fruit. Within this study we characterize the host response to $P$. citricarpa using the three main terms of "immune," "resistant," and "susceptible" as just defined and within the context of fresh fruit production.

Reports of immunity and resistance to CBS are rare, and it has been stated that 


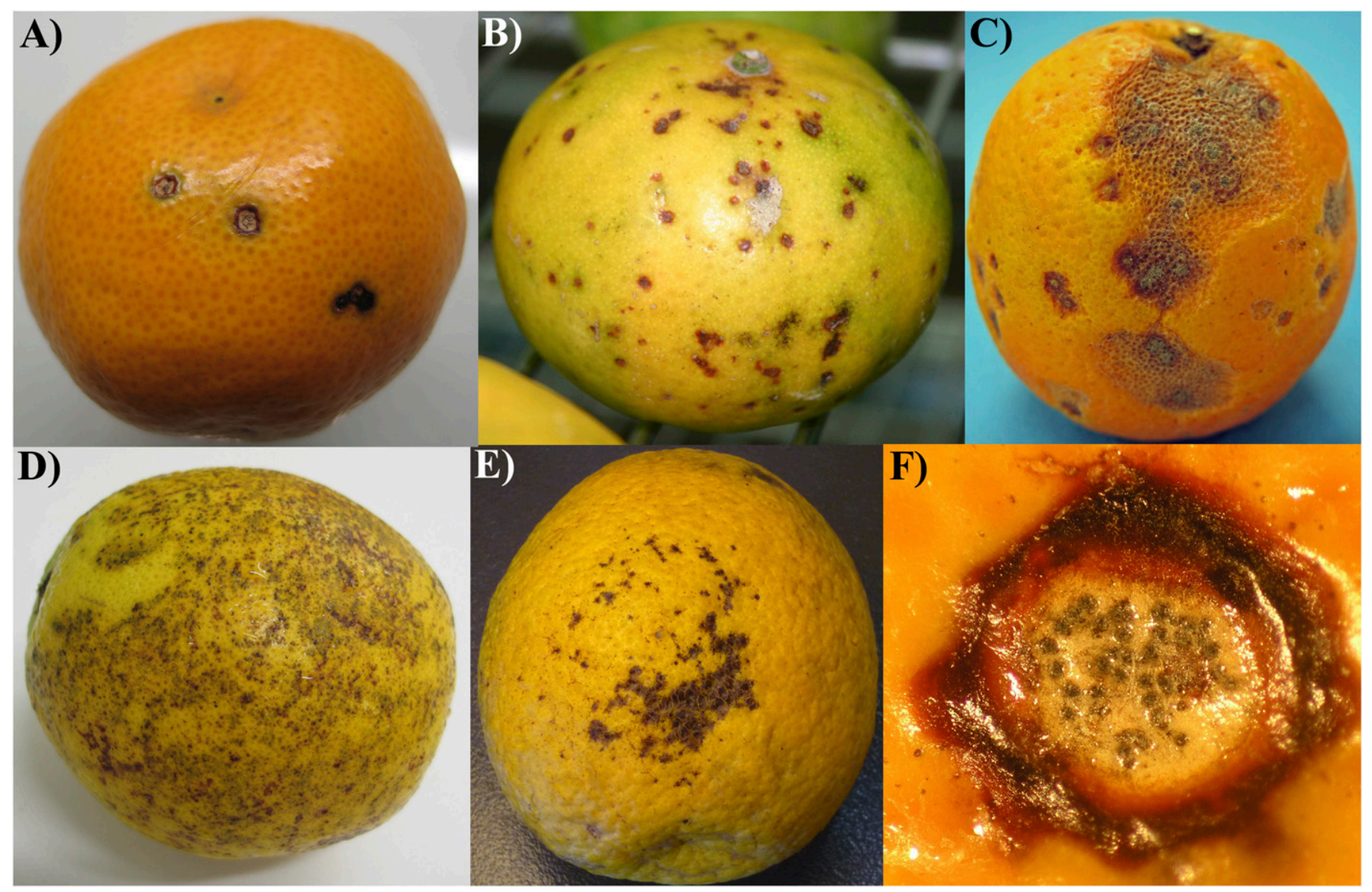

Fig. 1. Symptoms of citrus black spot incited by Phyllosticta citricarpa on fruit resulting from natural infection including (A) hard spot, (B) freckle spot, (C) virulent spot, (D) speckled blotch, (E) false melanose, and (F) a hard spot lesion containing pycnidia.

"all commercial citrus cultivars are susceptible to some degree" (Kotzé, 2000) and that "there are no known sources of resistance" to CBS (Machado et al., 2011). Resistance has only been reported for sour orange $(C$. xaurantium L.) and its hybrids, 'Tahiti' lime (C. Xlatifolia Yu. Tanaka), and the trifoliate orange [Poncirus trifoliata (L.) Raf.] (Aguilar-Vildoso et al., 2002; Baldassari et al., 2008; Kotzé, 1981). Even then, the reports of resistance in sour orange and

Received for publication 7 May 2019. Accepted for publication 1 July 2019

We thank the Citrus Research and Development Foundation (Grant no. 715) through the University of Florida and Hort Innovation (Grant no CT13021) for financial support of this project. We thank the Department of Agriculture and Fisheries for use of the germplasm collection and gratefully acknowledge the assistance from Deb Gultzow, Toni Newman, and Kathy Grice. NSW Department of Primary Industries provided some of the accessions used in testing. We also thank Ken Pegg, Mark Hoult, Stephen Mudge, and Jay Anderson for editorial input on the manuscript, and Superior Production Pty Ltd for making the lead author available to complete this manuscript.

A.K.M. is the corresponding author. E-mail: andrewmiles@2ph.com.au.

This is an open access article distributed under the CC BY-NC-ND license (http://creativecommons.org/ licenses/by-nc-nd/4.0/). trifoliate orange have not been demonstrated through specific inoculation experiments and are more likely based on anecdotal field observations. Lack of information on sources of resistance, and challenges in screening for disease resistance has hampered the potential for breeding for resistance to CBS, as well as it generally being considered unlikely to succeed (Calavan, 1960). Efforts have been further hindered by focusing on the use of sour orange as a source of resistance, which although apparently resulting in hybrids free of CBS symptoms (Rhodesia Agr. J., 1974) also transmits many undesirable fruit traits, such as bitterness (Matsumoto, 1995). Identifying sources of resistance that possess better fruit quality characteristics would therefore greatly advance genetic improvement for CBS resistance. In addition, access to segregating populations would assist in studies of the genetics and heritability of resistance and may support the development of breeding tools such as marker assisted breeding strategies.

Exploiting resistance to black spot on citrus fruit requires an appreciation of the genetic relationship among citrus accessions being evaluated as hosts. The long history of cultivation, frequent occurrence of apomixis, and ease with which interspecific hybrids can be generated have resulted in genetically diverse citrus accessions. Consequently, many apomictic interspecific hybrids have mistakenly acquired species status, including important commercial types such as grapefruit ( $C$. ×paradisi Macfad.), lemon ( $C$. Xlimon (L.) Osbeck), limes [C. Xaurantifolia (Christm.) Swingle, and $C$. $\times$ latifolia], sour orange (C. ×aurantium), and sweet orange $[C$. Xsinensis (L.) Osbeck]. However, a series of molecular studies (Carbonell-Caballero et al., 2015; Curk et al., 2015; Wu et al., 2014, 2018; Yu et al., 2018) has confirmed the original views of Scora (1975) and findings of Barrett and Rhodes (1976) that cultivated citrus are highly heterozygous interspecific admixtures of just a few basic taxa. Those base taxa are now considered to be $C$. reticulata Blanco; $C$. maxima; $C$. medica L.; and C. micrantha Wester and Fortunella spp. (Wu et al., 2018). An understanding of these genetic relationships is important in the development of genetic solutions to CBS because disease-resistant citrus types can potentially be reconstituted from either CBS immune or resistant accessions of their base taxa. For example, the pummelo $(C$. maxima) is a progenitor of sweet orange, grapefruit, and sour orange (Barrett and Rhodes, 1976), of which sweet orange and grapefruit are susceptible to CBS, whereas sour orange is resistant. This observation suggests to us that segregation for CBS resistance took place during the formation of current commercial citrus types from their pummelo progenitor. Consequently, 
efforts to breed CBS-resistant cultivars could potentially utilize progenitor accessions with CBS resistance, rather than use the highly heterozygous sour orange, which also has pronounced bitterness in both carpellary membranes and albedo (Hodgson, 1967). The recent insights into the genetic makeup of citrus cultivars allows reconstructing modern cultivars incorporating resistance and accelerate the breeding process.

In the case of the pathogen, the literature needs to be interpreted with care because there has been confusion regarding the various Phyllosticta spp. associated with Citrus spp. and related plant species. Currently, there are five pathogenic species associated with citrus: $P$. citricarpa, causing CBS on a wide range of citrus; $P$. paracitricarpa Guarnaccia $\&$ Crous, shown to be pathogenic to detached sweet orange fruit (Guarnaccia et al., 2017); P. citriasiana Wulandari (Wulandari et al., 2009) and P. citrimaxima Wikee, Crous, K.D. Hyde \& McKenzie (Wikee et al., 2013b), associated with tan spot of pummelo; and $P$. citrichinaensis Wang, Hyde and Li associated with symptoms on leaves and fruit of pummelo, sweet orange, and mandarin (C. reticulata) (Wang et al., 2012). The latter three Phyllosticta spp. have only been reported from specific regions of Asia, and P. paracitricarpa from Greece and China (Guarnaccia et al., 2017). Before 2009, P. citricarpa was considered the only pathogenic Phyllosticta sp. associated with citrus. Similarly, the number of endophytic species of Phyllosticta has proliferated. Before 2011, the only endophytic species was Guignardia mangiferae Roy (Baayen et al., 2002), but subsequent revisions have designated $P$. capitalensis Henn, $P$. citribraziliensis C. Glienke \& Crous, and $P$. paracapitalensis as the endophytic Phyllosticta spp. associated with citrus (Glienke et al., 2011; Guarnaccia et al., 2017). Confusion between the pathogenic and endophytic Phyllosticta spp. likely means that past references to $P$. citricarpa having an extensive host range within and outside of Citrus spp. (Kiely, 1948) may be incorrect. It is more likely that the endophytic Phyllosticta spp. which occur in a wide range of woody plants (Baayen et al., 2002; Guarnaccia et al., 2017; McOnie, 1964b; Wikee et al., 2013a) were commonly misidentified as $P$. citricarpa. In the specific case of Australia, only the pathogen $P$. citricarpa and the endophytes $P$. capitalensis and $P$. paracapitalensis have been confirmed from citrus (Miles et al., 2013; Tran et al., 2019).

Host resistance to CBS would be beneficial to citrus producers and consumers as it would break the reliance on chemical control, reduce exposure to fungicide residues on fruit, eliminate direct losses of fruit due to cosmetic downgrading and fruit drop, and overcome trade restrictions on fruit from production areas where CBS is present. An important first step toward achieving this goal is to identify immune or resistant phenotypes using a practical and reliable field inoculation method using a well character- ized isolate of the pathogen. Therefore, the overall objective of our study was to develop a field inoculation and assessment method to characterize the CBS phenotype of fruit of a wide range of citrus accessions. The specific questions we sought to address include 1) can reproducible expression of CBS symptoms on fruit be achieved through field inoculation? 2) can fruit immunity or resistance to CBS be accurately identified among a range of different citrus accessions? and 3 ) is there segregation for disease expression among hybrid progeny derived from immune, resistant, and susceptible parental accessions? Robust characterization of resistance or immunity among accessions of different genetic backgrounds presents the opportunity to breed for CBS resistance.

\section{Materials and Methods}

To address the aims of our study, we conducted field inoculations in the germplasm arboretum located at the Department of Agriculture \& Fisheries, Bundaberg Research Station, Queensland, Australia. This arboretum was ideal for the study because of the wide variety of citrus accessions available, the low level of CBS in the Bundaberg area, and the absence of fungicide applications. Our overall experimental approach was to inoculate fruit in the field with $P$. citricarpa and use water and the endophyte $P$. paracapitalensis as negative controls. Each year of the experiment, we included fruit of known susceptible accessions (e.g., sweet orange and mandarin) and putatively resistant accessions (e.g., sour orange and sour orange hybrids). Forty-nine accessions (Table 1) were inoculated based on relevant reports in the literature, an absence of CBS during previous field observations, and the importance of the accessions to our scion breeding program. Approximately 20 young fruitlets were inoculated on each accession, but the final number of fruit reaching maturity was highly dependent on the fruit set of each tree and the number of fruit that were free from other rind blemishes such as wind rub that may disrupt successful infection and accurate assessment of the expression of symptoms. Young hybrid plants that were producing fruit for the first time gave variable fruit numbers for inoculation.

Fungal isolates and inoculum preparation. Cultures of $P$. citricarpa (ex-type accession BRIP 52614) and $P$. paracapitalensis (BRIP 54242) were retrieved from the Queensland Plant Pathology Herbarium (BRIP). These two accessions have had their identity and pathogen/endophyte status confirmed recently (Miles et al., 2013; Tran et al., 2019). For inoculations in the 2013 season, we prepared inoculum following the methods of Baldassari et al. (2009). Leaf discs (10 $\mathrm{mm}$ diameter) were extracted from unsprayed mature leaves of C. reticulata 'Imperial' and then autoclaved and immediately placed abaxial side down into partially solidified water agar plates. Small blocks of mycelium from 2-week-old colonies of the Phyllosticta spp. on half strength potato dextrose agar (PDA, BD Difco, BD Australia) were placed adjacent to the leaf discs and incubated at $25^{\circ} \mathrm{C}$ under a 12-h cycle of black light and white light for $14 \mathrm{~d}$. Pycnidia readily formed on the surface of the leaf discs after $14 \mathrm{~d}$. In subsequent seasons, Phyllosticta colonies were established on half PDA for $14 \mathrm{~d}$ as previously described and were then flooded with sterile distilled water and left to stand for $30 \mathrm{~min}$ to induce spore release. Spore suspensions were then decanted into a centrifuge tube and adjusted to a concentration of $5 \times 10^{4}$ spores $/ \mathrm{mL}$ using a haemocytometer.

Field inoculation. We inoculated 8- to 12-week-old fruit in the field in 2013, 2014, and 2015 that had not been treated with fungicides. Two inoculation methods were used. In 2013, fruit were lightly misted with distilled water before a colonized leaf disc was held pycnidia side down against the surface of the fruit with moistened cotton wool surgical dressing. The fruit was then wrapped in domestic cling wrap and aluminium foil to maintain moisture and reflect field heat. To facilitate germination, penetration, and colonization, fruit remained wrapped for $7 \mathrm{~d}$ initially, but later batches of inoculations were wrapped for $48 \mathrm{~h}$ only. Control fruit were misted with water before the cotton wool, cling wrap, and foil were applied. In 2014 and 2015, we modified the inoculation procedure. After misting the fruit with water, we wrapped a $5 \mathrm{~mm}$ wide strip of sterile blotting paper soaked in the spore suspension around the entire equator of the fruit. The blotting paper was then covered with a strip of domestic cling wrap to maintain high moisture conditions. Finally, we wrapped the entire fruit in aluminium foil to reflect field heat. The foil, cling wrap, and blotting paper were removed from the fruit after $48 \mathrm{~h}$. Negative control fruit were inoculated in the same manner, but the blotting paper strip was soaked in water or a spore suspension of $P$. paracapitalensis.

Incubation and disease evaluation. After inoculation, fruit were left on the trees to reach maximum fruit maturity. Fruit nearing maturity were surrounded with a mesh bag to prevent losses from abscission. Abscised and mature fruit were taken to the laboratory for inspection. We inspected fruit under a dissecting microscope for symptoms of CBS and the presence of pycnidia and conidia of Phyllosticta. When no symptoms were visible, the fruit were incubated at $27{ }^{\circ} \mathrm{C}, 80 \%$ relative humidity, and permanent light for as long as possible (up to $127 \mathrm{~d}$ ) to maximize expression of CBS symptoms (Brodrick and Rabie, 1970). When symptoms of CBS were evident, the presence of symptoms with or without pycnidia and conidia of Phyllosticta was noted. After visual inspection and light microscopy, fruit were surface disinfested by swabbing with $70 \%$ ethanol, and small pieces of symptomatic tissue were plated onto half PDA to recover any Phyllosticta colonies. Fruit that failed to produce CBS symptoms during incubation were tested for the presence 


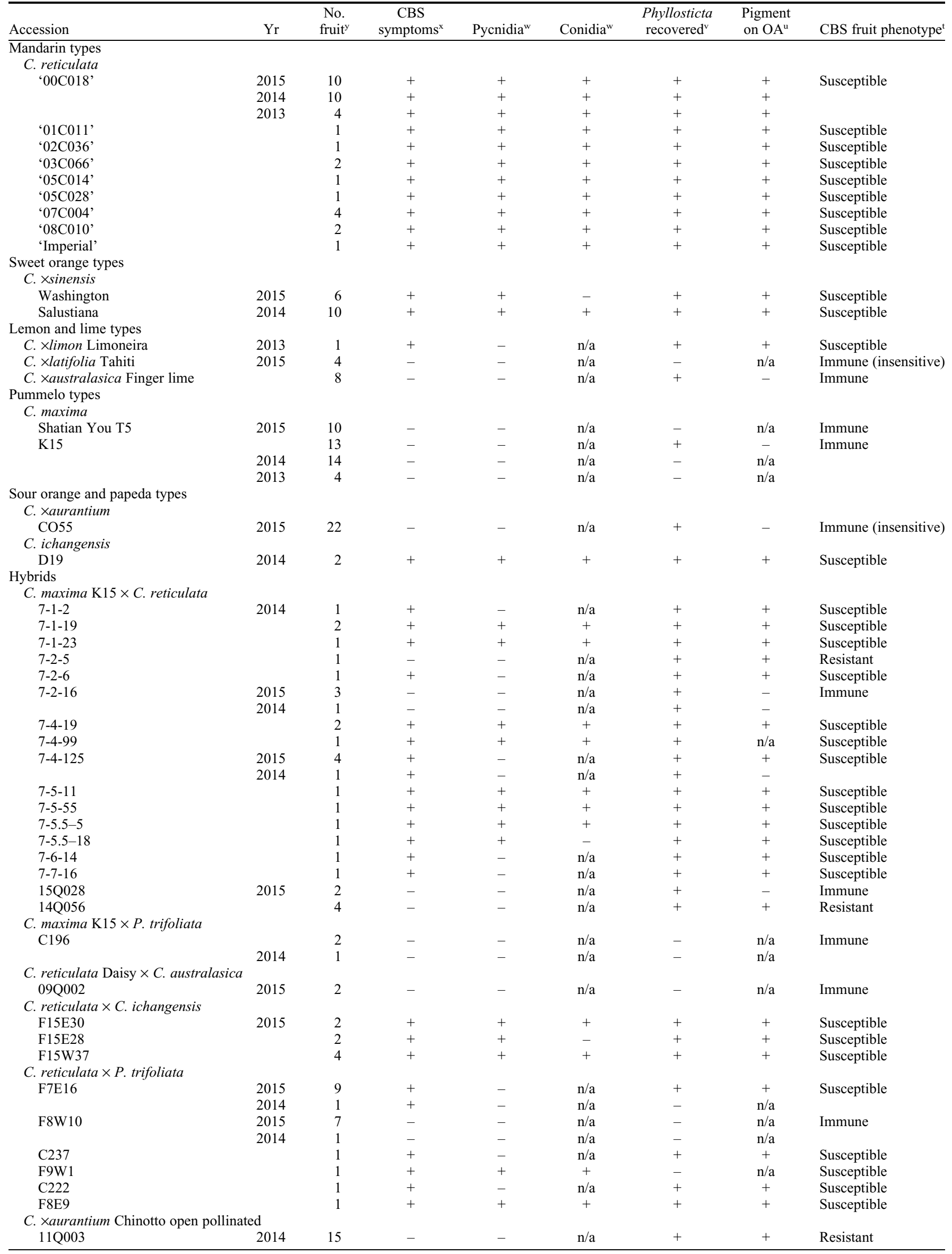


Table 1. (Continued) Details and results of inoculation studies to determine the citrus black spot (CBS) phenotype of 49 citrus accessions. ${ }^{\mathrm{z}}$

\begin{tabular}{|c|c|c|c|c|c|c|c|c|}
\hline Accession & Yr & $\begin{array}{l}\text { No. } \\
\text { fruit }^{y}\end{array}$ & $\begin{array}{c}\text { CBS } \\
\text { symptoms }^{x}\end{array}$ & Pycnidia $^{w}$ & Conidia $^{w}$ & $\begin{array}{c}\text { Phyllosticta } \\
\text { recovered }^{\mathrm{v}}\end{array}$ & $\begin{array}{c}\text { Pigment } \\
\text { on } \mathrm{OA}^{\mathrm{u}}\end{array}$ & CBS fruit phenotype \\
\hline \multicolumn{9}{|l|}{ C. $\times$ aurantium hybrid } \\
\hline \multirow[t]{2}{*}{ Gou tou Cheng D2 } & 2014 & 13 & + & + & + & + & + & Susceptible \\
\hline & 2013 & 11 & + & - & $\mathrm{n} / \mathrm{a}$ & + & + & \\
\hline \multirow[t]{2}{*}{ Gou tou Cheng D3 } & 2014 & 13 & + & + & + & + & + & Susceptible \\
\hline & 2013 & 7 & + & - & $\mathrm{n} / \mathrm{a}$ & + & + & \\
\hline \multicolumn{9}{|l|}{ Water inoculations } \\
\hline \multirow[t]{2}{*}{$00 \mathrm{C} 018$} & 2015 & 10 & - & - & $\mathrm{n} / \mathrm{a}$ & - & $\mathrm{n} / \mathrm{a}$ & $\mathrm{n} / \mathrm{a}$ \\
\hline & 2014 & 4 & - & - & $\mathrm{n} / \mathrm{a}$ & - & $\mathrm{n} / \mathrm{a}$ & $\mathrm{n} / \mathrm{a}$ \\
\hline Imperial & 2013 & 1 & - & - & $\mathrm{n} / \mathrm{a}$ & - & $\mathrm{n} / \mathrm{a}$ & $\mathrm{n} / \mathrm{a}$ \\
\hline Salustiana & 2014 & 3 & - & - & $\mathrm{n} / \mathrm{a}$ & + & - & $\mathrm{n} / \mathrm{a}$ \\
\hline \multirow[t]{2}{*}{ Gou tou cheng D3 } & & 4 & - & - & $\mathrm{n} / \mathrm{a}$ & + & - & $\mathrm{n} / \mathrm{a}$ \\
\hline & 2013 & 3 & - & - & $\mathrm{n} / \mathrm{a}$ & + & - & $\mathrm{n} / \mathrm{a}$ \\
\hline Gou tou cheng D2 & & 3 & - & - & $\mathrm{n} / \mathrm{a}$ & + & - & $\mathrm{n} / \mathrm{a}$ \\
\hline P. paracapitalensis inoculations & & & - & & & & & \\
\hline \multirow[t]{2}{*}{$00 \mathrm{C} 018$} & 2015 & 10 & - & - & $\mathrm{n} / \mathrm{a}$ & - & $\mathrm{n} / \mathrm{a}$ & $\mathrm{n} / \mathrm{a}$ \\
\hline & 2014 & 3 & - & - & $\mathrm{n} / \mathrm{a}$ & - & $\mathrm{n} / \mathrm{a}$ & $\mathrm{n} / \mathrm{a}$ \\
\hline Salustiana & & 4 & - & - & $\mathrm{n} / \mathrm{a}$ & + & - & $\mathrm{n} / \mathrm{a}$ \\
\hline Gou tou cheng D3 & & 4 & - & - & $\mathrm{n} / \mathrm{a}$ & + & - & $\mathrm{n} / \mathrm{a}$ \\
\hline
\end{tabular}

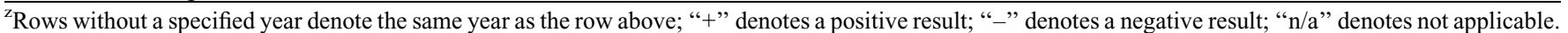
${ }^{\mathrm{y}}$ Number of fruit collected at fruit maturity.

${ }^{\mathrm{x}}$ Symptoms included hard spot, freckle spot, virulent spot, false melanose, and speckled blotch.

${ }^{\mathrm{w}}$ Presence of pycnidia with or without conidia consistent with those of Phyllosticta spp. as determined by light microscopy.

${ }^{v}$ Colonies of Phyllosticta spp. recovered onto half strength potato dextrose agar.

${ }^{\mathrm{u}}$ Colonies of $P$. citricarpa produce a yellow pigment surrounding the colony when grown on oatmeal agar (OA), whereas $P$. paracapitalensis does not.

${ }^{t}$ Phenotypes designated as susceptible (CBS symptoms and $P$. citricarpa recovered), resistant (no CBS symptoms and $P$. citricarpa recovered); and immune (no

CBS symptoms and no P. citricarpa recovered). Phenotype in parentheses denotes the phenotype reported by Baldassari et al. (2008) and Wickert et al. (2009).

of the pathogen by plating small pieces of tissue from the fruit equator onto half PDA just before the fruit decaying from other postharvest conditions such as mould. We then subcultured colonies of Phyllosticta arising from the plated tissue onto plates of oatmeal agar (OA, BD Difco, BD Australia) and incubated plates as previously described for $7 \mathrm{~d}$. Colonies were identified as either P. citricarpa or an endophytic Phyllosticta spp. based on the presence or absence a yellow pigment around the colony margins (Baayen et al., 2002; Baldassari et al., 2007; Guarnaccia et al., 2017; Tran et al., 2019). We considered fruit with CBS symptoms to be susceptible, resistant when there were no visible CBS symptoms but $P$. citricarpa could be recovered from the inoculation point, and immune where no CBS symptoms were visible and $P$. citricarpa could not be recovered.

\section{Results}

Our inoculation method using the sporesoaked blotting paper strip applied around the equator of the fruit resulted in typical CBS symptoms that were reproduced over different seasons and were consistent for different citrus accessions. These symptoms included hard spot (Fig. 2A), freckle spot, and virulent spot (Fig. 2B and D), and false melanose (Fig. 2C). The lesions developed around the equator of fruit, corresponding with the area of inoculation (Fig. 2A-D). The colonized leaf disc inoculation method used in the 2013 season produced CBS symptoms on fruit of susceptible control accessions. However, it often produced extreme symptoms of virulent spot that are not commonly observed after natural infection (Fig. 2E), even when we reduced the incubation time from $7 \mathrm{~d}$ to
48 h. These extreme symptoms sometimes included the development of an atypical pycnidial crust (Fig. 2F).

A total of 49 control fruit that reached maturity in the field after inoculation with water or $P$. paracapitalensis were incubated to induce symptoms. Approximately 250 samples were taken from inoculated tissue for fungal isolations. In no case did our inoculations with water or $P$. paracapitalensis result in CBS symptoms or the recovery of $P$. citricarpa (Table 1). However, colonies not producing a yellow pigment on OA were commonly recovered from tissue inoculated with both water and $P$. paracapitalensis, suggesting a background level of naturally occurring endophytic Phyllosticta spp. at our field trial.

The production of pycnidia within tissue symptomatic of CBS was consistent for the major commercial citrus "types," but pycnidia production within lesions was less frequent among susceptible hybrids with a pummelo or trifoliate orange parent. For example, '7-4-125' and 'F7E16' expressed CBS symptoms on multiple fruit from which $P$. citricarpa could be recovered, but no pycnidia were formed within the lesions even after the fruit were incubated (Table 1). Furthermore, it was rare that we observed pycnidia not producing conidia. $P$. citricarpa was frequently recovered from most symptomatic tissue. Accessions where $\geq 10$ fruit were subjected to fungal isolation resulted in a recovery rate greater than $70 \%$. For example, the accession '00C018' showed a recovery rate of $80 \%$, 'Gou tou cheng D2' of $85 \%$, 'Gou tou cheng D3' of $77 \%$, and 'Salustiana' of $100 \%$ (data not shown). The only exception to this was the hybrid 'F9W1', which still produced pycnidia and conidia consistent with Phyllosticta. In contrast to the high recovery rate of $P$. citricarpa from symptomatic tissue, recovery of $P$. citricarpa from asymptomatic tissue at the point of inoculation with $P$. citricarpa was rare, occurring in only three ('7-2-5', '14Q056', '11Q003') of the 49 accessions that were inoculated. In the case of '11Q003', we recovered $P$. citricarpa from only 2 of 15 $(13 \%)$, of the asymptomatic fruit we inoculated with $P$. citricarpa.

Immunity or resistance to CBS was identified in a low number of accessions (Table 1). The immunity of lime and sour orange types shown in Table 1 supports previous observations of resistance (Baldassari et al., 2008); however, we did not recover $P$. citricarpa from our inoculated lime and sour orange fruit. In contrast, the immunity of both accessions of pummelo was a novel finding. For the remaining citrus types (mandarin, sweet orange, lemon, and papeda) that were inoculated, the majority of fruit were found to be susceptible, in particular the mandarin and sweet orange types. These included the 'Washington' navel orange, which is well known to be susceptible to CBS in the field (Kiely, 1948). Within the lemon and lime types, the representative 'Limoneira' lemon was susceptible as expected.

There was preliminary evidence of segregation for resistance and immunity to CBS among hybrids generated using pummelo $(C$. maxima), trifoliate orange ( $P$. trifoliata), and finger lime $(C$. australasica) as parents (Table 1). In the case of pummelo, crosses were made previously using 'K15' (CBS immune) as the seed parent with various mandarin cultivars (CBS susceptible) as the pollen parent. Seventeen hybrid progeny from these crosses produced sufficient fruit for screening (Table 1). Of these two ('7-2-5' 


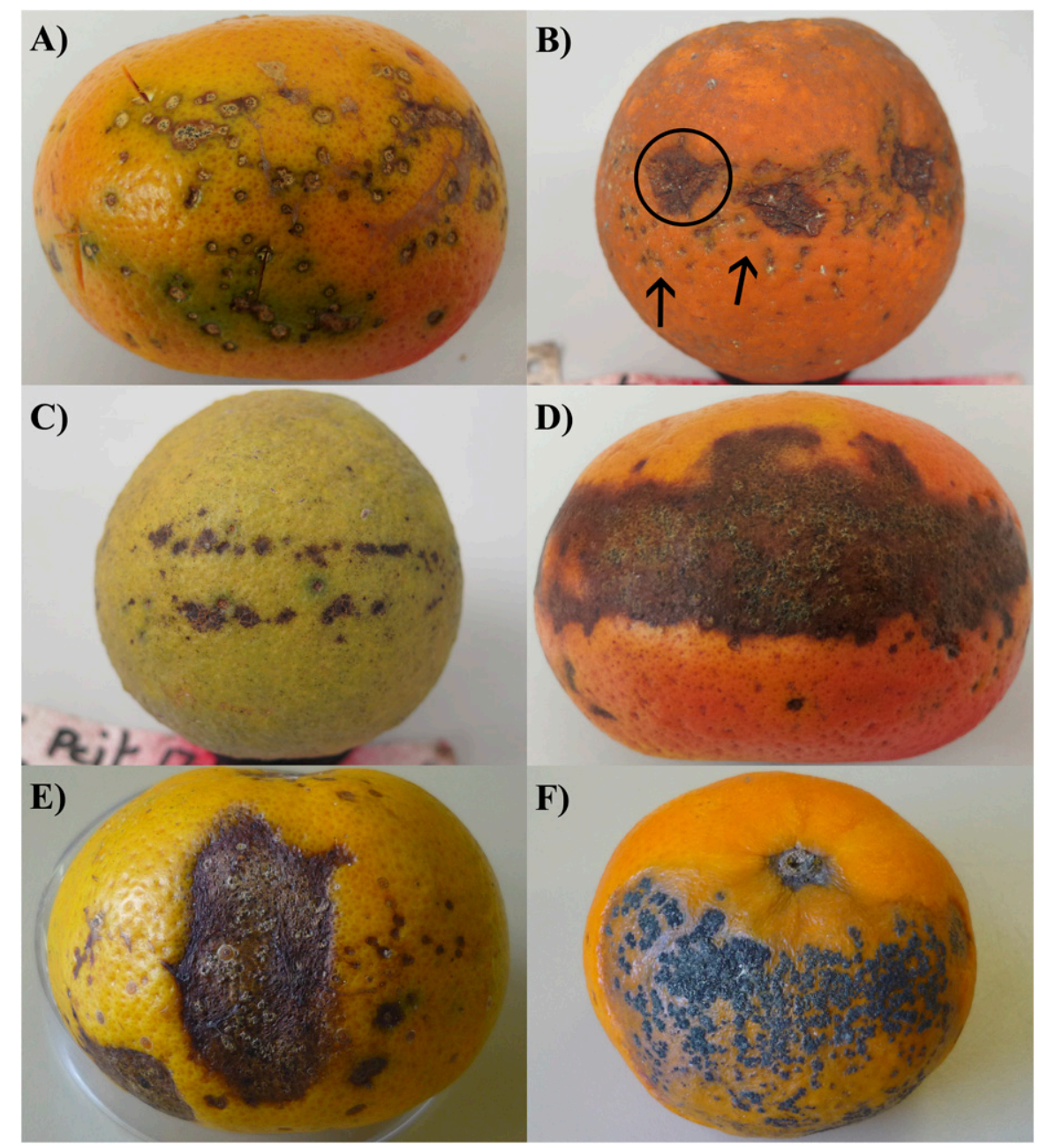

Fig. 2. Symptoms of citrus black spot resulting from inoculation of citrus fruit using conidia of Phyllosticta citricarpa and the equatorial blotting paper strip method. (A) Hard spot, (B) freckle (e.g., arrows) and virulent spot (e.g., circle), (C) false melanose, and (D) virulent spot containing pycnidia. Inoculation using the colonized leaf disk method resulted in severe symptoms including virulent spot (E) and the production of an extensive pycnidial crust $(\mathbf{F})$.

and '14Q056') were resistant, whereas another two hybrids ('7-2-16' and '15Q028') appeared to be immune to CBS. An additional family resulting from a cross of ' $\mathrm{K} 15$ ' pummelo as the seed parent with trifoliate orange had only one hybrid with sufficient fruit for inoculation, and this hybrid ('C196') was also found to be immune. Likewise, when using trifoliate orange as the pollen parent in crosses with mandarins, one ('F8W10') of the six screened hybrid progeny was found to be immune, further suggesting a role of trifoliate orange in transmitting CBS immunity. Similarly, the potential for finger lime to transmit immunity is supported by the hybrid '09Q002' (mandarin $\times$ fingerlime), which did not develop CBS symptoms, nor could evidence of $P$. citricarpa colonisation be found.

\section{Discussion}

In this study, we characterized the susceptibility, resistance, or immunity to CBS in fruit of a wide range of accessions of citrus using a simple novel in-field inoculation technique. Our results demonstrate that the pummelo accessions 'K15' and 'Shatian Yu', as well as $C$. australasica, are immune to $P$. citricarpa. Inoculated fruit of these accessions never produced any CBS symptoms, nor could $P$. citricarpa be recovered from the inoculated tissue at fruit maturity. To our knowledge, this is the first evidence that these particular citrus types are immune to $P$. citricarpa. Furthermore, our study provides evidence for segregation in CBS expression among hybrid progeny using $C$. maxima or $C$. australasica as a parent, based on the occurrence of a low number of immune hybrids with ' $\mathrm{K} 15$ ' and the immune phenotype of the C. australasica hybrid '09Q002'. In these examples, the immune parent has been hybridized with susceptible accessions that are themselves complex hybrids involving 'Ellendale', 'Imperial', and 'Murcott' mandarins, all of which are susceptible to CBS. Our findings demonstrate that immunity to CBS is a heritable trait that can be exploited in future breeding programs. Apart from $C$. maxima and C. australasica and some of their hybrid progeny, almost all accessions were found to be susceptible to CBS consistent with previous reports (Baldassari et al., 2008; Kotzé, 1981), including the known susceptible control accessions. In contrast, the true sour orange ('CO55') included in our study was free of CBS symptoms, consistent with previous reports (Wickert et al., 2009), whereas the sour orange hybrids included in our study ('Gou tou cheng D2' and 'Gou tou cheng D3') (Lee and Keremane, 2013; Zhang et al., 1988) were shown to be susceptible to CBS. Observing the expected CBS expression in known resistant and susceptible cultivars demonstrates that reliable expression of CBS symptoms can be achieved using our in-field inoculation method on fruit.

The pummelo fruit inoculated in our study were well within the age when citrus fruit are considered susceptible to $P$. citricarpa; fruit were repeatedly inoculated over multiple seasons; and yet fruit remained free of CBS and $P$. citricarpa while known susceptible accessions readily produced CBS symptoms. This demonstration of the immunity of pummelo to CBS is consistent with the lack of reports of the disease from commercial ' $\mathrm{K} 15$ ' pummelo production areas in tropical regions of Australia, where in many cases fruit are produced without fungicide applications. This tropical environment is highly conducive to CBS, and although the disease has been present in this region for at least 100 years, there is no official or anecdotal report of it ever having being detected on 'K15' or any other pummelo cultivar, nor have surveys of pummelo identified symptoms of CBS (Miles et al., 2013). Similarly, our results showing $C$. australasica to be immune are consistent with the absence of CBS symptoms on finger lime fruit observed during a survey of the New South Wales Department of Primary Industries Gosford Horticultural Institute arboretum located in a region of coastal New South Wales, which is subject to severe CBS pressure (Donovan et al., 2009). In addition, no CBS has been observed on commercial consignments of finger lime during 15 official CBS inspections for export certification by the Queensland Government, Department of Agriculture and Fisheries. Such surveys and inspections have been required based on a previously held assumption that all Citrus spp. are susceptible to CBS. Poncirus trifoliata is also sometimes assumed to be susceptible (European Plant Protection Organisation, 2018), but we were unable to include a true $P$. trifoliata in this study because of a lack of fruit on our accession to confirm the host status. However, three observations in our study would be consistent with a report of $P$. trifoliata being resistant (Aguilar-Vildoso et al., 2002). First, a $C$. maxima $\times P$. trifoliata accession 'C196' was found to be immune, possibly representing an immune $\times$ immune/resistant cross. Second, a C. reticulata $\times P$. trifoliata accession 'F8W10' was found to be immune, alongside susceptible siblings, possibly demonstrating segregation resulting from susceptible $\times$ immune/resistant cross. Third, there was an observed trend for reduced pycnidia 
formation within lesions of the susceptible $P$. trifoliata hybrids. Although not conclusive, these findings highlight the need to clarify the host status of $P$. trifoliata.

The observed immunity of the pummelo accessions to $P$. citricarpa may have been previously overlooked because of confusion between CBS symptoms and tan spot symptoms on pummelo incited by $P$. citriasiana, $P$. citrichinaensis, and $P$. citrimaxima (Wang et al., 2012; Wikee et al., 2013b; Wulandari et al., 2009). In the case of Australia, neither CBS or tan spot have been observed on pummelo, nor has $P$. citriasiana, $P$. citrichinaensis, or $P$. citrimaxima been identified among Australian accessions of Phyllosticta (Miles et al., 2013). It is also possible that pummelo accessions vary in their host response to CBS and that we have selected two that are immune. A wider range of $C$. maxima germplasm needs to be tested to confirm whether there is variation in the CBS expression of symptoms among different pummelo cultivars. It would also be beneficial to undertake companion inoculation studies with $P$. citriasiana, $P$. citrichinaensis, $P$. citrimaxima, and the recently described $P$. paracitricarpa (Guarnaccia et al., 2017) to confirm the pathogenicity of these species to pummelo and act as a positive control for $P$. citricarpa inoculations. Because these species are exotic fungi, it was not possible to include them in our pathogenicity tests.

Both immunity or resistance to $P$. citricarpa, particularly in pummelo, and its potential heritability are valuable breeding resources when aiming to combine immunity to CBS with high fruit quality. The two pummelo accessions we used in this study were selected for their desirable fruit quality traits, such as flavor, rind thickness, shape, and skin texture from a collection of more than 30 named and seedling pummelos evaluated at Bundaberg Research Station between 1998 and 2010. Pummelo is an ancestral taxon of sweet orange and grapefruit, and of most modern mandarin and lemon cultivars (Curk et al., 2015; Wu et al., 2018). The desirable commercial traits, such as eating quality, combined with observed immunity to CBS, create a major new opportunity in breeding, particularly when considering our preliminary evidence for segregation of immunity/resistance in its hybrid progeny. Although fruit numbers for inoculating were generally low in this study (because of the young age of the trees), they were sufficient to confirm that the majority of hybrids were susceptible to CBS. However, a small number of hybrids (e.g., the pummelo hybrid ' $7-2-16$ ' and the trifoliate orange hybrid 'F8W10') were immune in replicate fruit and repeated seasons. Therefore, it may now be possible to reconstitute key commercial cultivars using immune pummelo accessions as the base taxa through conventional hybridization breeding. This novel approach could prove more efficient and effective than hybridizing existing commercial cultivars with sour orange accessions as attempted previously
(Rhodesia Agr. J., 1974). To have identified CBS immunity in pummelo accessions with commercially desirable traits augers well for the introgression of disease resistance into new cultivars of sweet orange, grapefruit, and mandarin.

We have demonstrated that pummelo is immune to infection by $P$. citricarpa, rather than resistant. Meanwhile, pummelo is reported to be susceptible to tan spot incited by $P$. citriasiana, $P$. citrichinaensis, and $P$. citrimaxima (Wang et al., 2012; Wikee et al., 2013b; Wulandari et al., 2009). This observation for pummelo provides researchers with a model system for studying aspects such as the comparative infection processes of the various Phyllosticta spp.; the possible mechanisms underpinning the differential susceptibility of pummelo to the various Phyllosticta spp., as well as the opportunity to further investigate the heritability of immunity. Such future studies would benefit from the equatorial strip inoculation method developed in this study. The strip method was fast to implement $(\approx 100$ fruit per hour, with two field operators) and resulted in typical expression of CBS symptoms, from a controlled inoculum dose at a known location on the fruit surface. Also worthy of note is the recent demonstration of equivalent pathogenicity of $P$. citricarpa conidia and ascospores (Tran et al., 2018), which supports the use of our simple conidia-based inoculation method.

Although this study may help to renew interest in breeding for resistance to CBS, rapid genetic progress remains hindered by the reliance on fruit to characterize the resistant phenotype of potential parents and their progeny. This hindrance is in contrast to the progress that has been made in breeding for resistance to alternaria brown spot incited by Alternaria alternata (Fr.) Keissl. (Pegg, 1966), and citrus scab incited by Elsinoë fawcettii Bitancourt and Jenkins (Timmer et al., 1996), which has been possible because of the large-scale screening of young seedlings based on the rapid expression of disease symptoms on leaves instead of fruit (Miles et al., 2015; Smith et al., 2016). Consequently, the next major step forward in breeding for CBS resistance will most likely come from the development of a leaf-based screening approach to identify immune or resistant individuals. Leaf-based screening would improve breeding efficiency by culling susceptible hybrids many years before they would have commenced fruiting, thus removing field maintenance costs and freeing up resources to establish large populations of CBS-resistant hybrids segregating for other important commercial traits. A leaf-based approach may be either by direct pathogen screening or eventually molecular approaches, but either way, the relationship of leaf to fruit susceptibility first needs to be established. The relationship between leaf and fruit susceptibility is important because 'Tahiti' lime and sour orange fail to produce CBS symptoms on fruit, but ascospores can be produced in their leaf litter (Baldassari et al., 2008; Wickert et al., 2009) suggesting that the fruit-leaf relationship is not simple with respect to CBS. It has also been reported that $P$. citricarpa can be isolated from asymptomatic fruit of the 'Tahiti' lime, and the term 'insensitive' was proposed to describe resistant hosts that can also be a source of inoculum (Baldassari et al., 2008), but in our study, we did not recover $P$. citricarpa from the inoculated 'Tahiti' lime tissue. The recent demonstration of reproducible foliar symptom development in 'Troyer' citrange $(C$. sinensis $\times P$. trifoliata) (Tran et al., 2018) may provide new opportunities for further studying the susceptibility of leaves and fruit. In the short term, it is likely that breeding efforts will need to characterize accessions in terms of both fruit and leaf reaction. This may be needed to account for the direct economic effect on fruit, as well as indirect effects from inoculum produced in leaf litter that could infect adjacent, susceptible citrus cultivars in a mixed commercial planting.

Immunity and resistance of citrus to $P$. citricarpa remain poorly understood after more than a century since CBS was first described. Past confusion over host and pathogen taxonomy, and the subsequent inability to routinely screen germplasm, are partly responsible for this lack of progress. However, new opportunities have arisen from this study, including a simple inoculation method to characterize expression of CBS symptoms in germplasm, strong evidence for immunity to $P$. citricarpa in pummelo and some other accessions, and preliminary evidence for immunity and resistance to CBS being a heritable trait. In addition, recent research concerning the genetic makeup and pedigree of all major citrus types and their progenitors may enable breeders and pathologists to recreate commercially important cultivars while capturing resistance to CBS. There is little doubt that introgression of immunity or resistance to CBS in commercially desirable citrus cultivars would greatly benefit citrus producers and consumers worldwide.

\section{Literature Cited}

Aguilar-Vildoso, C.I., J.G.B. Ribeiro, E. Feichtenberger, A. de Goes, and M.B. Spósito. 2002. Resistência, p. 27-28. Manual técnico de procedimentos da mancha preta dos citros. Ministerio da Agricultura, Pecuaria e Abastecimento, Secretaria de Defesa Agropecuaria, Departamento de Defesa e Inspecao Vegetal, Brazil.

Baayen, R.P., P.J.M. Bonants, G. Verkley, G.C. Carroll, H.A. van der Aa, M. de Weerdt, I.R. van Brouwershaven, G.C. Schutte, W. Maccheroni, Jr., C. Glienke de Blanco, and J.L. Azevedo. 2002. Nonpathogenic isolates of the citrus black spot fungus, Guignardia citricarpa, identified as a cosmopolitan endophyte of woody plants, $G$. mangiferae (Phyllosticta capitalensis). Phytopathology 92:464-477.

Baldassari, R.B., I. Brandimarte, A.G. Andrade, D.C.G. de Souza, C. de Moretto, and A. de Goes. 2007. Induction of the precoce expression of Guignardia citricarpa symptoms in fruits of Pera-Rio sweet orange. Rev. Bras. Frutic. 29:269-275. 
Baldassari, R.B., R.F. Reis, and A. de Goes. 2006. Susceptibility of fruits of the 'Valencia' and 'Natal' sweet orange varieties to Guignardia citricarpa and the influence of the coexistence of healthy and symptomatic fruits. Fitopatol. Bras. 31:337-341.

Baldassari, R.B., R.F. Reis, and A. de Goes. 2009. A new method for inoculation of fruit with Guignardia citricarpa, the causal agent of citrus black spot. Eur. J. Plant Pathol. 123:1-4.

Baldassari, R.B., E. Wickert, and A. de Goes. 2008. Pathogenicity, colony morphology and diversity of isolates of Guignardia citricarpa and $G$. mangiferae isolated from Citrus spp. Eur. J. Plant Pathol. 120:103-110.

Barrett, H.C. and A.M. Rhodes. 1976. A numerical taxonomic study of affinity relationships in cultivated Citrus and its close relatives. Syst. Bot. 1:105-136.

Brentu, F., K. Oduro, S. Offei, G. Odamtten, A. Vicent, N. Peres, and L. Timmer. 2012. Crop loss, aetiology, and epidemiology of citrus black spot in Ghana. Eur. J. Plant Pathol. 133:657-670.

Brodrick, H.T. and C.J. Rabie. 1970. Light and temperature effects on symptom development and sporolation of Guignardia citricarpa Kiely, on Citrus sinenisis (Linn) Osbeck. Phytophylactica 2:157-164.

Calavan, E.C. 1960. Black spot of citrus. California Citrograph 46:22-24.

Carbonell-Caballero, J., R. Alonso, V. Ibañez, J. Terol, M. Talon, and J. Dopazo. 2015. A phylogenetic analysis of 34 chloroplast genomes elucidates the relationships between wild and domestic species within the genus Citrus. Mol. Biol. Evol. 32:2015-2035.

Curk, F., G. Ancillo, F. Ollitrault, X. Perrier, J.-P. Jacquemoud-Collet, A. Garcia-Lor, L. Navarro, and P. Ollitrault. 2015. Nuclear speciesdiagnostic SNP markers mined from 454 amplicon sequencing reveal admixture genomic structure of modern citrus varieties. PLoS One 10:e0125628.

D'Arcy, C.J., D.M. Eastburn, and G.L. Schumann. 2001. Illustrated glossary of plant pathology. The Plant Health Instructor. The American Phytopathological Society, Saint Paul. 31 Jan. 2019. <http://www.apsnet.org/ edcenter/illglossary/pages/default.aspx $>$.

de Goes, A., R.B. Baldassari, E. Feichtenberger, M.B. Spósito, and C.I. Aguilar-Vildoso. 2000. Cracked spot, a new symptom of citrus black spot (Guignardia citricarpa) in Brazil. Proc. of the Intl. Soc. of Citriculture, p. 145.

Donovan, N.J., P. Barkley, and S. Hardy. 2009. Hosts of citrus scab, brown spot and black spot in coastal NSW. Proceedings of the 17th Australasian Plant Pathology Society Conference, p. 146.

European Plant Protection Organisation. 2018. EPPO global database. European Plant Protection Organisation. 15 Dec. 2018. <https:// gd.eppo.int/taxon/GUIGCI/pathwayshosts>.

Glienke, C., O.L. Pereira, D. Stringari, J. Fabris, V. Kava-Cordeiro, L. Galli-Terasawa, J. Cunnington, R.G. Shivas, J.Z. Groenewald, and P.W. Crous. 2011. Endophytic and pathogenic Phyllosticta species, with reference to those associated with citrus black spot. Persoonia 26:47-56.

Guarnaccia, V., J.Z. Groenewald, H. Li, C. Glienke, E. Carstens, V. Hattingh, P.H. Fourie, and P.W Crous. 2017. First report of Phyllosticta citricarpa and description of two new species, $P$. paracapitalensis and $P$. paracitricarpa, from citrus in Europe. Stud. Mycol. 87:161-185.

Hodgson, R.W. 1967. Horticultural varieties of citrus, p. 431-588. In: W. Reuther, H.J. Webber, and L.D. Batchelor (eds.). The citrus industry. University of California, Berkley, CA.

Kiely, T.B. 1948. Preliminary studies on Guignardia citricarpa, n.sp.: The ascigerous stage of Phoma citricarpa McAlp. and its relation to black spot of citrus. Proc. Linn. Soc. N. S. W. 73:249-292.

Korf, H.J.G., G.C. Schutte, and J.M. Kotzé. 2001. Effect of packhouse procedures on the viability of Phyllosticta citricarpa, anamorph of the citrus black spot pathogen. Afr. Plant Prot. 7:103-109.

Kotzé, J.M. 1981. Epidemiology and control of citrus black spot in South Africa. Plant Dis. 65:945-955.

Kotzé, J.M. 2000. Black spot, p. 23-25. In: L.W. Timmer, S.M. Garnsey, and J.H. Graham (eds.). Compendium of citrus diseases. Phytopathological Society Press, Inc., St. Paul, MN.

Lanza, F.E., T.G. Metzker, T. Vinhas, F. Behlau, and G.J. Silva, Junior. 2018. Critical fungicide spray period for citrus black spot control in São Paulo State, Brazil. Plant Dis. 102:334-340.

Lee, R.F. and M.L. Keremane. 2013. Mild strain cross protection of tristeza: A review of research to protect against decline on sour orange in Florida. Front. Microbiol. 4:259.

Loest, F.C. 1968. Influence of pruning citrus trees on the efficacy of control of black spot (Guignardia citricarpa Kiely). The South African Citrus J. 419:15.

Machado, M.A., M. Cristofani-Yaly, and M. Bastianel. 2011. Breeding, genetic and genomic of citrus for disease resistance. Rev. Bras. Frutic. 33:158-172.

Matsumoto, R. 1995. Studies on genetics of bitterness of citrus fruit and application to breeding of bitterless citrus cultivars with special reference to the bitterness caused by flavanone glycosides. Bul. of the Fruit Tree Res. Sta., Extra special issue 6:1-74.

McAlpine, D. 1899. Anthracnose, or "black spot", p. 21-22. In: R.S. Brain (ed.). Fungus diseases of citrus trees in Australia, and their treatment. Department of Agriculture Victoria, Melbourne, Australia.

McOnie, K.C. 1964a. Source of inoculum of Guignardia citricarpa, the citrus black spot pathogen. Phytopathology 54:64-67.

McOnie, K.C. 1964b. The latent occurrence in citrus and other hosts of a Guignardia easily confused with $G$. citricarpa, the citrus black spot pathogen. Phytopathology 54:40-43.

McOnie, K.C. 1967. Germination and infection of citrus by ascospores of Guignardia citricarpa in relation to control of black spot. Phytopathology 57:743-746.

Miles, A.K., T.K. Newman, D.L. Gultzow, S.C. Parfitt, A. Drenth, and M.W. Smith. 2015. Commercial-scale alternaria brown spot resistance screening as the first step in breeding new mandarins for Australia. Acta Hort. 1065:971978.

Miles, A.K., Y.P. Tan, M.K. Tan, N.J. Donovan, A. Ghalayini, and A. Drenth. 2013. Phyllosticta spp. on cultivated citrus in Australia. Australas. Plant Pathol. 42:461-467.

Miles, A.K., S.L. Willingham, and A.W. Cooke 2004. Field evaluation of strobilurins and a plant activator for the control of citrus black spot. Australas. Plant Pathol. 33:371-378.

Miles, A.K., P. Wyatt, R. Kopittke, M. Eelkema, B Missenden, E. Hamacek, M. Shivas, and A. Drenth. 2008. Integrated disease management of citrus black spot (Guignardia citricarpa Kiely) in Queensland, Australia. 11th International Citrus Congress. Wuhan, China 26-30 Oct. 2008).

Pegg, K.G. 1966. Studies of a strain of Alternaria citri Pierce, the causal organism of brown spot of Emperor mandarin. Queensland J. Agr. Animal Sci. 23:15-28.

Rhodesia Agr. J. 1974. Progress with citrus breeding against black spot. Rhodesia Agr. J. 71:60.

Schubert, T.S., M.M. Dewdney, N.A. Peres, M.E. Palm, A. Jeyaprakash, B. Sutton, S.N. Mondal, N.-Y. Wang, and J. Rascoe. 2012. First report of citrus black spot caused by Guignardia citricarpa on sweet orange [Citrus sinensis (L.) Osbeck] in North America. Plant Dis. 96:1225.

Schutte, G.C. and J.M. Kotzé. 1997. Grass mulching as part of an integrated control programme for the control of citrus black spot. Citrus J. $7: 18-20$.

Schutte, G.C., R.I. Mansfield, H. Smith, and K.V. Beeton. 2003. Application of azoxystrobin for control of benomyl-resistant Guignardia citricarpa on Valencia oranges in South Africa. Plant Dis. 87:784-788.

Scora, R.W. 1975. On the history and origin of Citrus. Bull. Torrey Bot. Club 102:369-375.

Silva, Jr., GJ., M.S. Scapin, F.P. Silva, A.R.P. Silva, F. Behlau, and H.H. Ramos. 2016. Spray volume and fungicide rates for citrus black spot control based on tree canopy volume. Crop Prot. 85:38-45.

Smith, M.W., D.L. Gultzow, T.K. Newman, S.C. Parfitt, and A.K. Miles. 2016. A co-inoculation technique to rapidly screen citrus hybrids for resistance to both alternaria brown spot caused by Alternaria alternata and citrus scab caused by Elsinoë fawcettii. Citrus Res. Technol. 37:82-87.

Spósito, M.B., L. Amorim, R.B. Bassanezi, A. Bergamin Filho, and B. Hau. 2008. Spatial pattern of black spot incidence within citrus trees related to disease severity and pathogen dispersal. Plant Pathol. 57:103-108.

Timmer, L.W., M. Priest, P. Broadbent, and M.K Tan. 1996. Morphological and pathological characterization of species of Elsinoë causing scab diseases of citrus. Phytopathology 86:1032-1038.

Tran, N., A.K. Miles, R.G. Dietzgen, M. Dewdney, K. Zhang, J.A. Rollins, and A. Drenth. 2017 Sexual reproduction in the citrus black spot pathogen, Phyllosticta citricarpa. Phytopathology 107:732-739.

Tran, N.T., A.K. Miles, R.G. Dietzgen, and A. Drenth. 2019. Phyllosticta capitalensis and $P$. paracapitalensis are endophytic fungi that show potential to inhibit pathogenic $P$. citricarpa on citrus. Australas. Plant Pathol.

Tran, N.T., A.K. Miles, M.W. Smith, R.G. Dietzgen, and A. Drenth. 2018. Pathogenicity of Phyllosticta citricarpa ascospores on Citrus spp. Plant Dis. 102:1386-1393.

Truter, M.P. 2010. Epidemiology of citrus black spot disease in South Africa and its impact on phytosanitary trade restrictions. University of Pretoria, South Africa, PhD Diss. Abstr. D10/ $708 /$ ag.

Wager, V.A. 1952. The black spot disease of citrus in South Africa. Sci. Bull Dept. Agr. South Africa 303:1-52.

Wang, N.-Y., K. Zhang, J.C. Huguet-Tapia, J.A. Rollins, and M.M. Dewdney. 2016. Mating type and simple sequence repeat markers indicate a clonal population of Phyllosticta citricarpa in Florida. Phytopathology 106:13001310.

Wang, X., G. Chen, F. Huang, J. Zhang, K. Hyde, and H. Li. 2012. Phyllosticta species associated with citrus diseases in China. Fungal Divers. 52:209-224.

Wickert, E., A. De Goes, E. Gertrudes De Macedo Lemos, A. de Souza, E. Leandro Da Silveira, F. Pereira, and D. Rinaldo. 2009. Phylogenetic 
relationships and diversity of Guignardia spp isolated from different hosts on ITS1-5,8SITS2 region. Rev. Bras. Frutic. 31:360-380.

Wikee, S., L. Lombard, P. Crous, C. Nakashima, K. Motohashi, E. Chukeatirote, S. Alias, E.C. McKenzie, and K. Hyde. 2013a. Phyllosticta capitalensis, a widespread endophyte of plants. Fungal Divers. 60:91-105.

Wikee, S., L. Lombard, C. Nakashima, K. Motohashi, E. Chukeatirote, R. Cheewangkoon, E.H.C. McKenzie, K.D. Hyde, and P.W. Crous. 2013b. A phylogenetic re-evaluation of Phyllosticta (Botryosphaeriales). Stud. Mycol. 76:1-29.

Wu, G.A., S. Prochnik, J. Jenkins, J. Salse, U. Hellsten, F. Murat, X. Perrier, M. Ruiz, S. Scalabrin, J. Terol, M.A. Takita, K. Labadie, J. Poulain, A. Couloux, K. Jabbari, F. Cattonaro, C. Del Fabbro, S. Pinosio, A. Zuccolo, J. Chapman,
J. Grimwood, F.R. Tadeo, L.H. Estornell, J.V Munoz-Sanz, V. Ibanez, A. Herrero-Ortega, P. Aleza, J. Perez-Perez, D. Ramon, D. Brunel, F. Luro, C. Chen, W.G. Farmerie, B. Desany, C. Kodira, M. Mohiuddin, T. Harkins, K. Fredrikson, P. Burns, A. Lomsadze, M. Borodovsky, G. Reforgiato, J. Freitas-Astua, F. Quetier, L. Navarro, M. Roose, P. Wincker, J. Schmutz, M. Morgante, M.A. Machado, M. Talon, O. Jaillon, P. Ollitrault, F. Gmitter, and D. Rokhsar. 2014 Sequencing of diverse mandarin, pummelo and orange genomes reveals complex history of admixture during citrus domestication. Nat. Biotechnol. 32:656-662.

Wu, G.A., J. Terol, V. Ibanez, A. López-García, E. Pérez-Román, C. Borredá, C. Domingo, F.R. Tadeo, J. Carbonell-Caballero, R. Alonso, F. Curk, D. Du, P. Ollitrault, M.L. Roose, J.
Dopazo, F.G. Gmitter, D.S. Rokhsar, and M. Talon. 2018. Genomics of the origin and evolution of Citrus. Nature 554:311-316.

Wulandari, N.F., C. To-anun, K.D. Hyde, L.M. Duong, J. de Gruyter, J.P. Meffert, J.Z. Groenewald, and P.W. Crous. 2009. Phyllosticta citriasiana sp nov., the cause of citrus tan spot of Citrus maxima in Asia. Fungal Divers. 34:23-39.

Yu, Y., C. Chen, M. Huang, Q. Yu, D. Du, M.R. Mattia, and F.G. Gmitter. 2018. Genetic diversity and population structure analysis of citrus germplasm with single nucleotide polymorphism markers. J. Amer. Soc. Hort. Sci. 143:399-408.

Zhang, T.M., X.Y. Liang, and C.N. Roistacher. 1988. Occurrence and detection of Citrus Tatter Leaf Virus (CTLV) in Huangyan, Zhejiang Province, China. Plant Dis. 72:543-545. 